\title{
A Pilot Evaluation of Associations Between Displayed Depression References on Facebook and Self-reported Depression Using a Clinical Scale
}

\author{
Megan Andreas Moreno, MD, MSEd, MPH \\ Dimitri A. Christakis, MD, MPH \\ Katie G. Egan, BSN \\ Lauren A. Jelenchick, BS \\ Elizabeth Cox, MD, PhD \\ Henry Young, PhD \\ Hope Villiard \\ Tara Becker, PhD
}

\begin{abstract}
The objective of this study was to determine associations between displayed depression symptoms on Facebook and self-reported depression symptoms using a clinical screen. Public Facebook profiles of undergraduates from two universities were examined for displayed depression references. Profiles were

Address correspondence to Megan Andreas Moreno, MD, MSEd, MPH, Department of Pediatrics, Section of Adolescent Medicine, University of Wisconsin, 2,870 University Ave, Suite 200, Madison, WI 53705, USA. Phone: +1-608-2653710; Fax: +1-608-2630722; Email: mamoreno@pediatrics.wisc.edu.

Lauren A. Jelenchick, BS, Department of Pediatrics, Section of Adolescent Medicine, University of Wisconsin, Madison, WI, USA. Phone: +1-608-2653710; Fax: +1-608-2630503; Email: lajelenchick@pediatrics.wisc.edu

Elizabeth Cox, MD, PhD, Department of Pediatrics, Section of Adolescent Medicine, University of Wisconsin, Madison, WI, USA. Phone: +1-608-2639104; Email: ecox@pediatrics.wisc.edu

Hope Villiard, Department of Pediatrics, Section of Adolescent Medicine, University of Wisconsin, Madison, WI, USA. Phone: +1-608-2653710; Fax: +1-608-2630503; Email: hvillard@wisc.edu

Dimitri A. Christakis, MD, MPH, Department of Pediatrics, University of Washington, PO Box 5371, Seattle, WA, USA. Phone: +1-206-8848237; Email: Dimitri.christakis@seattlechildrens.org

Dimitri A. Christakis, MD, MPH, Seattle Children's Research Institute, Seattle, WA, USA.

Katie G. Egan, BSN, School of Nursing, University of Wisconsin-Madison, Madison, WI, USA. Phone: +1-608-8905437; Email:kgegan@wisc.edu

Henry Young, PhD, School of Pharmacy, University of Wisconsin-Madison, Madison, WI, USA. Phone: +1-608-8900367; Fax: +1-608-2625262; Email: hnyoung@pharmacy.wisc.edu

Tara Becker, PhD, Department of Biostatistics and Medical Informatics, University of Wisconsin-Madison, Madison, WI, USA. Phone: +1-608-2658052; Email: tbecker@biostats.wisc.edu
\end{abstract}

Journal of Behavioral Health Services \& Research, 2011. 295-304. (c) 2011 The Author(s). This article is published with open access at Springerlink.com 
categorized as depression symptom displayers or non-displayers. Participants completed an online PHQ-9 depression scale. Analyses examined associations between PHQ-9 score and depression symptom displayers versus non-displayers. The mean PHQ-9 score for non-displayers was 4.7 ( $S D=$ 4.0), the mean PHQ-9 score for depression symptom displayers was 6.4 (SD=5.1; $p=0.018)$. A trend approaching significance was noted that participants who scored into a depression category by their PHQ-9 score were more likely to display depression symptom references. Displayed references to depression symptoms were associated with self-reported depression symptoms.

\section{Introduction}

Depression among college students is common and the prevalence of depression diagnoses among college students has increased $56 \%$ in the last six years. ${ }^{1-3}$ Given that approximately half of young adults attend post-secondary education, colleges are an important setting in which mental health concerns such as depression must be addressed. ${ }^{4}$ The most common form of depression within the adolescent and young adult age group is major depressive disorder, which has a yearly incidence of approximately $8 \%{ }^{1,5,6}$ However, an additional $22 \%$ of adolescents and young adults suffer from "sub-diagnostic" levels of depressive symptoms. ${ }^{7}$ Both those with a major depression diagnosis and those with depression symptoms experience impaired functioning and morbidity. ${ }^{8}$ Adverse outcomes of depression include increased rates of substance use, comorbid psychiatric conditions, and suicide. ., $9-12^{-12}$

Despite the prevalence of depression in this population, college students struggling with depression symptoms are frequently undiagnosed as many students do not perceive a need for help or do not seek clinical services. ${ }^{1,6,13}$ Concerns about the stigma related to mental illness are also associated with less perceived need for help and decreased treatment seeking behavior. ${ }^{14}$ While $30 \%$ of college students report feeling so depressed in the last 12 months that it was difficult to function, only $10 \%$ of college students report seeking any type of mental health care in the past year. $^{3,}{ }^{15}$ Other barriers to help-seeking include lack of knowledge about available services and privacy concerns. ${ }^{1}$ Given the frequency and consequences of depression as well as the inadequacy of current help-seeking among college students, innovative methods to identify those at risk and provide them appropriate services are warranted.

Social networking web sites (SNSs) may present new opportunities to investigate depression among college students. Over $90 \%$ of college students use Facebook.com, the most popular SNS in this population. ${ }^{16-18}$ Previous work illustrates that computers elicit higher levels of self-disclosure and uninhibited personal expression. ${ }^{19-21}$ References to personal information or health risk behaviors, such as substance use and sexual behavior, are common on SNS profiles. ${ }^{2-24}$ Some college students display depression symptom references on "status updates," personally written text describing the profile owner's current experience or emotion. ${ }^{25}$ Examples include "Matt is feeling really depressed this week," or "Diane can't stop the tears." Previous work found that approximately a quarter of publicly available Facebook profiles by undergraduates display depression symptoms, and $2.5 \%$ of profiles display depression symptoms in patterns consistent with the Diagnostic and Statistical Manual (DSM-IV) criteria for a major depressive episode (MDE). As the majority of college students' profiles are public, this information is available to students' peers, instructors, health providers as well as others within that university Facebook network. ${ }^{18}$ Recent media stories highlight tragic suicides of young adults that were referenced on Facebook prior to being carried out; illustrating the urgent need to better understand the validity of displayed references to depression and other mental health concerns. ${ }^{26,27}$ The objectives of this pilot study were to examine the validity of references to depression symptoms on public Facebook profiles by comparing these references to self-reported depression symptoms using the Patient Health Questionnaire (PHQ-9) depression screening tool. 


\section{Methods}

This study was conducted between September 1, 2009 and September 15, 2010 and received IRB approval from both the University of Wisconsin and the University of Washington.

\section{Setting and subjects}

This study used the SNS Facebook (www.Facebook.com) as it is the most popular SNS among the target population of college students. ${ }^{28,} 29$ Publicly available Facebook profiles of undergraduate students who were members of two large state university Facebook networks were investigated. Profile owners were selected for the study if their reported age on the profile was between 18 and 20 years old and the profile showed evidence of activity in the last 30 days. Only profiles for which profile owners could be recruited to the study by calling a phone number listed on either the Facebook profile or the university directories were included.

\section{Profile selection}

Eligible profiles were identified by a random search of the freshmen, sophomore, and junior undergraduate classes at the two selected universities using the Facebook search engine. Because the Facebook search engine is subject to error, all profiles returned in the searches were reviewed manually to confirm inclusion criteria were met. Profiles were excluded if they did not meet search criteria, including those who were not undergraduates $(n=448)$, did not meet the age criteria $(n=313)$, or did not display their age $(n=49)$. Profiles were also excluded due to privacy settings that prevented identification of depression symptoms, including having any one of the following sections set to private: information section, wall, or photographs $(n=1,630)$, or if a profile examination revealed that they would not be reachable for recruitment as no contact information (phone number or email) was listed on the profile or in the university directory $(n=303)$. A total of 307 profiles met all inclusion criteria and were evaluated.

\section{Codebook and variables}

All eligible profiles were evaluated by one of three trained coders using a SNS research codebook, which was developed and used in previous work evaluating displayed depression symptom references on SNS profiles. ${ }^{23,}{ }^{25}$ From each SNS profile that met inclusion criteria, demographic data and displayed depression symptom reference data were recorded, including verbatim text from profiles. If present, identifiable information was removed from text references. References to depression symptoms were defined using the DSM-IV symptom criteria for a MDE. ${ }^{30}$ The criteria for MDE included depressed mood, loss of interest/pleasure in activities, appetite changes, sleep problems, psychomotor agitation or retardation, energy loss, feeling worthless or guilty, decreased concentration or suicidal ideation. ${ }^{30}$ Status updates were considered a depression symptom reference if they fit one of the described depression criteria by keyword or a synonym. For example, one symptom keyword of major depression is "hopeless," therefore a status update stating "I feel hopeless" would be coded as a reference to depression. The term "giving up" is a synonym of "hopeless," therefore, a status update disclosing "I feel like giving up" would be coded as a reference to depression. Status updates that clearly referenced a person other than the profile owner (i.e. "Matt is sitting next to me in class and he looks sad"), or references to the common situational experience of having a bad day (i.e. "I'm having a bummer of a day") were not considered depression references. 
Profiles were categorized into one of two groups. Profiles without any depression symptom references were considered "non-displayers." Profiles with one or more references to depression symptoms were considered "Depression Symptom Displayers."

\section{Profile evaluation}

First, the investigators viewed the "information section" of the profile to obtain demographic information and descriptive variables describing Facebook use. Second, to evaluate depression symptom disclosures, investigators reviewed each profile's status updates from the date of evaluation through the same date 1 year prior. For each status update that included a depression symptom, coders assessed whether the displayed symptom was a match to one of the DSM-IV criteria for a MDE. ${ }^{30}$ If so, they recorded verbatim text and the date of disclosure.

A $20 \%$ random subsample of profiles were evaluated by all three coders to test interrater reliability. Cohen's kappa statistic was used to evaluate the extent to which there was overall agreement in the coding of the presence or absence of depression symptom references on a profile. Cohen's kappa was 0.79 for depression symptom references. ${ }^{31}$

\section{Recruitment}

All profile owners whose profiles met inclusion criteria were telephoned. After verifying the profile owner's identity, the study was explained to the profile owner and permission was requested to send them an email that contained further information about the study. If the participant consented to receive the email, an email was sent to the profile owner's university email account that provided detailed information about the study as well as a link to the online survey. Two different links to identical surveys were used so as to obtain aggregate results without requiring personal identifiers. Subjects in the depression symptom displayer group were emailed a link to one survey; subjects in the non-displayer group were emailed a link to a separate but identical survey. The survey was administered online via a Catalyst WebQ online survey engine. Survey respondents were provided a $\$ 15$ iTunes gift card as compensation. A total of 307 profiles met inclusion criteria and from these, 224 eligible profile owners participated in the survey ( $73 \%$ response rate) and 215 participants completed all PHQ-9 questions and received a total score.

\section{Survey}

The survey evaluated depression using the Patient Health Questionnaire (PHQ-9) clinical screen for depression. This screen is based on DSM-IV criteria for a MDE and has been validated in adult and adolescent populations. ${ }^{5}, 32$ The scale inquires about frequency of depression symptoms experienced in the last two weeks, such as depressed mood and hopelessness. Response categories include: not at all, several days, nearly half the days, and nearly every day. PHQ-9 scores range from 0 to 27; a score of less than 5 suggests no depression, a score of 5 or greater suggests depression. Depression diagnostic categories are differentiated as follows: a score of 5-10 suggests the person has mild depression, a score of 11-15 indicates the person has moderate depression, and a score over 15 suggests moderately severe depression.

\section{Analysis}

All statistical analyses were conducted using STATA version 11.0 (Statacorp, College Station, TX). Displayed depression categories from Facebook data and demographic characteristics were summarized using descriptive statistics. Bivariate comparisons were performed using Fisher's exact test or Chi-squared tests. To examine associations between displayed depression references on 
Facebook and PHQ-9 score, two analyses were performed. First, zero-inflated negative binomial regression was used to examine the relationship between Depression Symptom Displayer/NonDisplayer as the predictor variable and PHQ-9 mean score as the outcome variable. Second, in an exploratory analysis, PHQ-9 scores were dichotomized to represent standard clinical categories: scores of 0 to 4 were considered not indicative of depression; any score 5 or above was indicative of depression (including mild, moderate, and moderately severe depression). Logistic regression was used to evaluate the relationship between depression symptom displayer/non-displayer as the predictor variable and the dichotomized PHQ-9 depression category as the outcome variable.

\section{Results}

\section{Subjects}

A total of 307 profiles met inclusion criteria and from these, 224 eligible profile owners participated in the survey ( $73 \%$ response rate) and 215 participants completed all PHQ- 9 questions and received a total score. Participants had an average age of $18.8(\mathrm{SD}=0.7)$, and were $54 \%$ female and $68 \%$ Caucasian. Approximately half of participants were from each university. Please see Table 1 for further descriptive information.

\section{Facebook displayed depression disclosures}

Of Facebook profiles coded, 33.9\% displayed depression symptoms. Depression symptom displayers were slightly younger $(p=0.04)$ and earlier in their college careers $(p=0.01)$ compared to non-displayers. Approximately $40 \%$ of depression symptom displayers were age 18 compared to

\section{Table 1}

Participant information

\begin{tabular}{lrcr}
\hline & Number & Percentage (\%) & Mean (SD) \\
\hline Age & 224 & & $18.8(0.7)$ \\
18 years & 77 & 34.4 & \\
19 years & 118 & 52.7 & \\
20 years & 29 & 12.9 & \\
Gender & & & \\
Male & 102 & 45.5 & \\
Female & 122 & 54.5 & \\
State & & & \\
Washington & 101 & 45.1 & \\
Wisconsin & 123 & 54.9 & \\
Race & & 67.9 & \\
Caucasian/White & 152 & 17.0 & \\
Asian & 38 & 3.6 & \\
Other & 8 & 7.6 & \\
Multiracial & 17 & 6.0 & \\
Missing & 9 & 64.1 & \\
Depression symptom display & 144 & 33.9 & \\
Non-displayer & 74 & \\
Depression symptom displayer & &
\end{tabular}


$31 \%$ of non-displayers. Women were more likely to display depression symptoms on Facebook than men, $40 \%$ of women were depression symptom displayers compared to only $25 \%$ of men. Table 2 illustrates these bivariate comparisons.

\section{PHQ-9 score}

PHQ-9 scores ranged from 0 to 27, with a mean of $5.2(\mathrm{SD}=4.5)$ and a median of 4 (IQR 2-11). Overall, 63\% of participants scored into the "No Depression" category based on PHQ scores. Using the standard cutoff for the PHQ-9, 27\% of participants' responses placed them in the mild depression category (scores between 5 and 9), 8\% of participants responses placed them in the moderate depression category (scores between 10 and 15), and 3\% responses placed them in the moderately severe depression category (scores over 15). Figure 1 illustrates the distribution of subjects across PHQ depression categories and by displayer/non-displayer status.

Table 2

Bivariate comparisons for depression non-displayers and depression symptom displayers

\begin{tabular}{|c|c|c|c|c|c|}
\hline & \multicolumn{2}{|c|}{ Depression non-displayer } & \multicolumn{2}{|c|}{ Depression symptom displayer } & \multirow[b]{2}{*}{$p$ value } \\
\hline & Number & Mean (SD)/\% & Number & Mean (SD)/\% & \\
\hline Age & 150 & $18.9(0.7)$ & 74 & $18.7(0.6)$ & 0.04 \\
\hline 18 years & 47 & $31.3 \%$ & 30 & $40.5 \%$ & \\
\hline 19 years & 78 & $52.0 \%$ & 40 & $54.1 \%$ & \\
\hline $20-21$ years & 25 & $16.7 \%$ & 4 & $5.4 \%$ & \\
\hline Graduation year & & & & & $0.01^{\mathrm{a}}$ \\
\hline 2011 & 14 & $9.3 \%$ & 1 & $1.4 \%$ & \\
\hline 2012 & 57 & $38.0 \%$ & 24 & $32.4 \%$ & \\
\hline $2013-2014$ & 71 & $47.3 \%$ & 49 & $66.2 \%$ & \\
\hline Gender & & & & & $0.01^{\mathrm{b}}$ \\
\hline Male & 77 & $51.3 \%$ & 25 & $33.8 \%$ & \\
\hline Female & 73 & $48.7 \%$ & 49 & $66.2 \%$ & \\
\hline State & & & & & $0.45^{\mathrm{b}}$ \\
\hline Washington & 65 & $43.3 \%$ & 36 & $48.6 \%$ & \\
\hline Wisconsin & 85 & $56.7 \%$ & 38 & $51.4 \%$ & \\
\hline Race & & & & & $0.66^{\mathrm{a}}$ \\
\hline Caucasian/White & 101 & $66.0 \%$ & 51 & $68.9 \%$ & \\
\hline Asian & 27 & $17.6 \%$ & 11 & $14.9 \%$ & \\
\hline Other & 4 & $2.6 \%$ & 4 & $5.4 \%$ & \\
\hline Multiracial & 11 & $7.2 \%$ & 6 & $8.1 \%$ & \\
\hline Missing & 7 & $4.6 \%$ & 2 & $2.7 \%$ & \\
\hline PHQ-9 score & 141 & $4.7(4.0)$ & 74 & $6.2(5.1)$ & $0.02^{\mathrm{c}}$ \\
\hline No depression & 95 & $62.1 \%$ & 40 & $54.1 \%$ & $0.22^{\mathrm{a}}$ \\
\hline Mild depression & 34 & $22.2 \%$ & 23 & $31.1 \%$ & \\
\hline Moderate depression & 9 & $5.9 \%$ & 8 & $10.8 \%$ & \\
\hline Serious depression & 3 & $2.0 \%$ & 3 & $4.1 \%$ & \\
\hline
\end{tabular}


Gender comparisons revealed that women had higher average PHQ-9 scores (mean $=6.4, \mathrm{SD}=4.7$, median $=5.0)$ compared to men $($ mean $=3.8, \mathrm{SD}=3.6$, median $=3.0)(p=0.001)$.

\section{PHQ-9 score and Facebook displayed depression}

Displayed depression symptom references on Facebook were positively associated with PHQ-9 scores. The mean PHQ-9 score non-displayers was $4.7(\mathrm{SD}=4.0$, median=3.0); the mean PHQ-9 score for depression symptom displayers was $6.4(\mathrm{SD}=5.1$, median=9.0) $(\exp (\mathrm{B})=1.31, \mathrm{SE}=0.11$, $p=0.018$ ).

Though it did not reach statistical significance $(p=0.056)$, there was a trend that suggested depression symptom displayers were more likely than non-displayers to score into one of the depression categories (mild, moderate, or severe) based on the PHQ-9 (OR $=1.75$, 95\% $\mathrm{CI}=0.99-3.13)$.

\section{Discussion}

This is the first study to demonstrate an association between specific content of displayed depression symptom references on Facebook and self-reported depression symptoms using a clinical scale. Findings suggest that depression symptom disclosures on SNSs may be representative of mild depression symptoms. Despite the potential for stigma surrounding mental health symptoms or diagnoses, a third of profiles in this study publicly displayed depression symptom references.

Findings are similar to previous work in which $30 \%$ of college students reported that in the last 12 months they have felt so depressed that it was difficult to function; a related study found that $33 \%$ of college students reported symptoms of depression. ${ }^{33}$ Findings in this study demonstrated that approximately $33 \%$ of participants displayed depression symptom references on Facebook.

This pilot evaluation suggests validity for these displayed depression symptom references. However, the mean score for displayers fell within the category of mild depression, rather than moderate or severe depression. Thus, results suggest that students may be using Facebook to

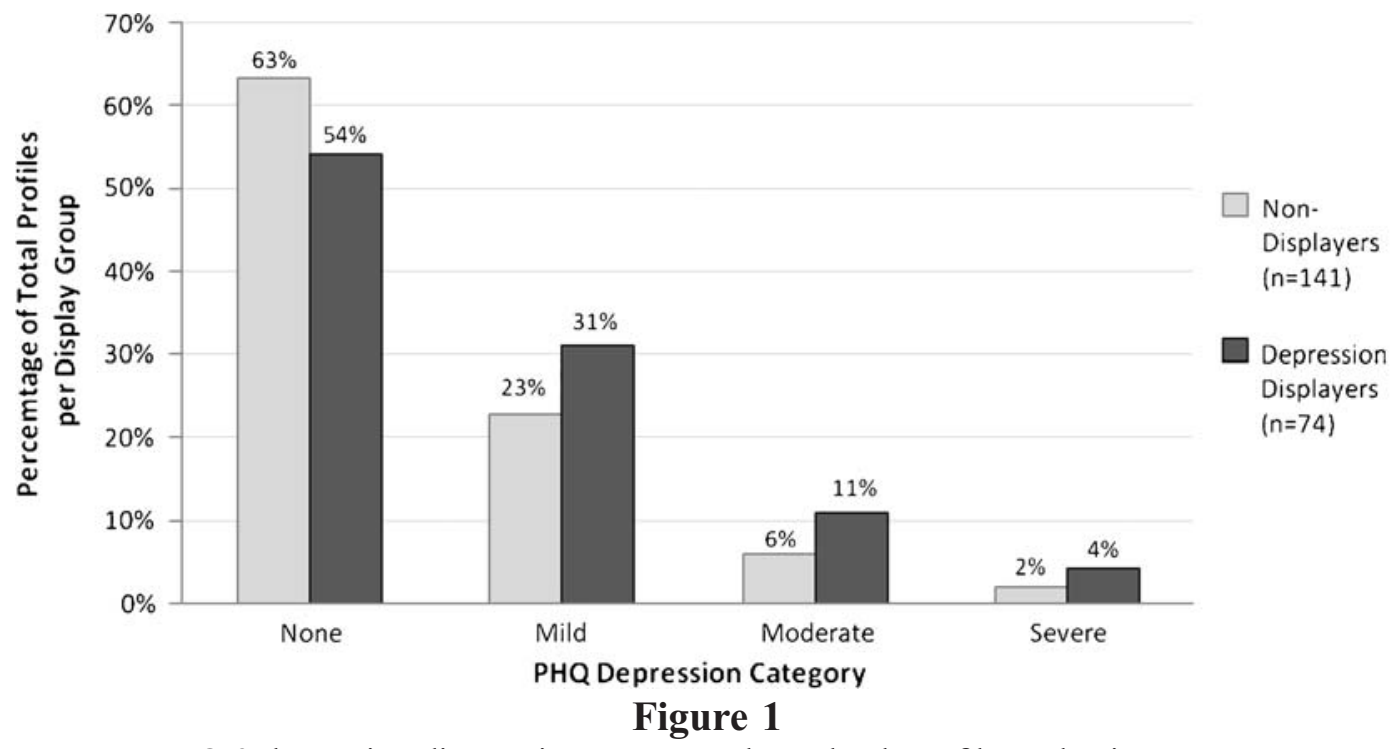

PHQ-9 depression diagnostic category and Facebook profile evaluation 
express and potentially receive support for mild depressive symptoms rather than a method to identify students at significant risk for severe depression. Alternative explanations are also possible. Since depression is more recognized as a common condition compared to generations ago, it may be more common for young adults to use these terms without embodying the true diagnostic meaning.

These preliminary findings do not suggest that Facebook should be used to formally diagnose depression; a diagnosis of depression is comprised of symptom patterns over time. Without clinical context including duration, severity, and frequency of the displayed symptoms, formal diagnosis cannot be without clinical evaluation. However, as Facebook displays are marked with a date, it would be possible to observe not only individual references but patterns over time. A previous study applied adapted DSM diagnostic criteria for a major depressive episode to Facebook using symptom and time criteria, and found that $2.5 \%$ of Facebook profile disclosures met criteria for a major depressive episode in the past year. ${ }^{34}$

There are several potential limitations of this study. First, this study evaluated Web profiles from only one SNS. The extent to which findings could be generalized to other SNSs is not known; however, Facebook is by far the most common SNS used by college students. Second, because this study focused on college students, generalizing results to other young adult populations may not be warranted. Given that college students are a key population in which mental health problems are common, consequential, and often undiagnosed, this was the population of choice for this evaluation. Third, this study focused on publicly available profiles, it is unclear whether increased privacy settings would increase or decrease the likelihood of disclosing depression symptoms. Although approximately half of the screened profiles were excluded due to privacy settings, at present a minority of college students report undergoing depression screening using a standardized instrument. ${ }^{3}$ The goal in assessing publicly available profiles was to examine profiles that could be accessed by any peer, parent, or college health provider. Finally, the PHQ-9 was not administered concurrently to when the depression symptom disclosure was displayed on Facebook, which may have weakened the strength of association between displayed depression symptoms and selfreported depression symptoms using the PHQ-9.

An important point to emphasize is that a lack of depression symptoms displayed on Facebook should not be reassuring that depression is not present. Findings do not suggest that Facebook displays of depression symptoms are an effective method to rule out depression, as many of the non-displayers PHQ-9 scores suggested depression. However, these findings are suggestive that displayed depression symptoms on Facebook are worthy of further investigation.

\section{Implications for Behavioral Health}

This study serves as a starting point to investigate displayed depression references on Facebook. There are several ways in which these findings could be used towards improving mental health care for college students. First, since Facebook is primarily a peer communication tool it is possible that peers may be both able and motivated to identify at-risk students using Facebook. While peers may not be uniformly knowledgeable about DSM-IV criteria for depression, many peers may be aware of or responsive to disclosures of distress and willing to learn more about how to better identify peers who are suffering from depression. It may be that this process is already taking place when college students display status updates and receive supportive comments from other online friends. Previous work has shown that adolescents often disclose more about themselves on SNSs than they do in person. ${ }^{35}$ In the future, campuses could consider educating resident advisors or peer leaders to encourage students whose Facebook profiles include repeated references to depression symptoms to seek further evaluation. Students often report willingness to refer their peers for help and over half of college students report interest in learning how to help a student in distress. ${ }^{3,36,37}$ 
Second, SNSs may provide new opportunities to increase student help-seeking behavior. It is possible that such screening could be triggered by the content of a SNS profile. When Facebook users view their profile, advertisements triggered by keywords present on the profile are displayed at the side of the profile. It is possible that university counseling centers could link messages about counseling services or links to online screening to keywords such as "depressed" or "hopeless." A recent study evaluated an interactive web-based program designed to screen students for depression and suicide risk. After the initial online screening, 24\% of students entered into an online dialog with a counselor, 19\% later attended an in-person session with the counselor, and $14 \%$ entered a treatment program. ${ }^{38} \mathrm{SNSs}$ may provide an innovative venue to provide access to online screening and follow-up resources.

All of these intervention ideas hinge on designing programs that are acceptable to students and respect their privacy and confidentiality. ${ }^{39,40}$ Mental health disclosures are potentially stigmatizing, thus, proper attention to privacy will be essential. However, there are reasons to be optimistic that today's college students may welcome online mental health programs. A study assessing a web-based intervention program found that among students with an unmet need for mental health care, over $90 \%$ reported interest in or intention to use the program. ${ }^{41}$ Given the difficulty in identifying students at risk for depression, and the potential negative consequences of untreated depression, providers cannot afford to ignore potential public health opportunities to reduce the burden of mental illness in this population.

This is the first study to illustrate an association between depression symptom disclosures on a publicly accessible SNS and self-reported depression symptoms. Findings illustrate that Facebook profile owners who chose to display one or more text references to depression symptoms on publicly available Facebook profiles had higher PHQ-9 scores. Further, results illustrate a trend that participants who were depressed, those who scored into the PHQ-9 category of depression, were more likely to display depression symptom disclosures on Facebook. Further studies should refine and expand these methods, as well as evaluate how to effectively communicate with older adolescents regarding health information displayed on SNSs. Further study could explore how students perceive depression disclosures by other students, and whether Facebook is providing an innovative source of support for students with depression symptoms.

\section{Acknowledgments}

This work was supported by award R211AA017936 from NIAAA as well as award K12HD055894 from NICHD. The authors wish to acknowledge the contributions of Libby Brockman, Lauren Kacvinsky, Megan Pumper, Mike Swanson, and Kaitlyn Bare to this project.

Open Access This article is distributed under the terms of the Creative Commons Attribution Noncommercial License which permits any noncommercial use, distribution, and reproduction in any medium, provided the original author(s) and source are credited.

\section{References}

1. Hunt J, Eisenberg D. Mental health problems and help-seeking behavior among college students. Journal of Adolescent Health. Jan 2010;46(1):3-10

2. National Survey of Couseling Center Directors, 2006. International Assoication of Counseling Services, Inc; 2007. http://www.education. pitt.edu/survey/nsccd/archive/2006/monograph.pdf. Accessed October 1, 2010.

3. Association ACH. American College Health Association: National College Health Assessment II: Reference Group Data Report Fall 2008. Baltimore: American College Health Association;2009.

4. Statistics NCE. Digest of Education Statistics: 2009. Washington, DC: US Department of Eduction, National Center for Education Statistics;2010.

5. Garlow SJ, Rosenberg J, Moore JD, et al. Depression, desperation, and suicidal ideation in college students: Results from the American Foundation for Suicide Prevention College Screening Project at Emory University. Depression and Anxiety. 2008;25 (6):482-488. 
6. Eisenberg D, Golberstein E, Gollust SE. Help-seeking and access to mental health care in a university student population. Medical Care. Jul 2007;45(7):594-601.

7. Yang J, Yao S, Zhu X, et al. The impact of stress on depressive symptoms is moderated by social support in Chinese adolescents with subthreshold depression: A multi-wave longitudinal study. Journal of Affective Disorders. Dec 2010;127(1-3):113-121.

8. Rohde P, Clarke GN, Lewinsohn PM, et al. Impact of comorbidity on a cognitive-behavioral group treatment for adolescent depression. Journal of American Academy of Child and Adolescent Psychiatry. Jul 2001;40(7):795-802.

9. Rao U. Links between depression and substance abuse in adolescents: Neurobiological mechanisms. American Journal of Preventive Medicine. 2006;31(6, Suppl 1):S161-S174.

10. Rao U, Chen LA. Characteristics, correlates, and outcomes of childhood and adolescent depressive disorders. Dialogues in Clinical Neuroscience. 2009;11(1):45-62.

11. Deas D, Brown ES. Adolescent substance abuse and psychiatric comorbidities. Journal of Clincial Psychiatry. Jul 2006;67(7):e02.

12. Kessler RC, Foster CL, Saunders WB, et al. Social consequences of psychiatric disorders I: Educational attainment. The American Journal of Psychiatry. 1995;152(7):1026-1032.

13. Zivin K, Eisenberg D, Gollust SE, et al. Persistence of mental health problems and needs in a college student population. Journal of Affective Disorders. Oct 2009;117(3):180-185.

14. Eisenberg D, Downs MF, Golberstein E, et al. Stigma and help seeking for mental health among college students. Medical Care Research and Review. Oct 2009;66(5):522-541.

15. Rosenthal B, Wilson WC. Mental health services: Use and disparity among diverse college students. Journal of American College Health. Jul-Aug 2008;57(1):61-68.

16. Ross C, Orr ES, Arseneault JM, et al. Personality and motivations associated with Facebook use. Computers in Human Behavior. 2009;25 (2):578-586.

17. Ellison NB, Steinfield C, Lampe C. The benefits of Facebook "Friends:" social capital and college students' use of online social network sites. Journal of Computer-Mediated Communication. 2007;12.

18. Lewis K, Kaufman J, Christakis N. The Taste for privacy: An analysis of college student privacy settings in an online social network. Journal of Computer-Mediated Communication. 2008;14(1):79-100.

19. Walther JB, Parks MR. Cues filtered out, cues filtered in: Computer mediated communication and relationships. In: Miller GR, ed. The handbook of interpersonal communication. Thousand Oaks: Sage; 2002:529-563.

20. Wallace P, Linke S, Murray E, et al. A randomized controlled trial of an interactive Web-based intervention for reducing alcohol consumption. Journal of Telemedicine and Telecare. 2006;12 Suppl 1:52-54.

21. Fleming PJ. Software and sympathy: therapeutic interaction with the computer. In: Fish SL, ed. Talking to strangers: Mediated therapeutic communication. Norwood: Ablex; 1990.

22. Hinduja S, Patchin JW. Personal information of adolescents on the Internet: A quantitative content analysis of MySpace. Journal of Adolescence. Feb 2008;31(1):125-146.

23. Moreno MA, Parks MR, Zimmerman FJ, et al. Display of health risk behaviors on MySpace by adolescents: Prevalence and associations. Archives of Pediatrics and Adolescent Medicine. 2009;163(1):35-41.

24. Moreno MA, Brockman LB, Wasserheit JW, et al. A pilot investigation of sexual reference display on Facebook: Are these references associated with sexual intention, sexual experience or risky sexual behavior? (in press). 2011.

25. Moreno MA, Jelenchick LA, Egan KG, et al. Feeling bad on Facebook: Depression disclosures by college students on a social networking site. Depressions and Anxiety. Jun 2011;28(6):447-455.

26. LaPook J. Preventing suicides. CBS.com; 2010.

27. George C. Experts offer tips to avert teen suicides. Houston Chronicle; 2010.

28. Google. Google Ad Planner. 2010; https://www.google.com/adplanner/planning/site_details\#siteDetails?identifier=facebook.com\&geo= US\&trait_type=1\&lp=false. Accessed April 16, 2010.

29. Pempek TA, Yermolayeva YA, Calvert SL. College students' social networking experiences on Facebook. Journal of Applied Developmental Psychology. 2009;20(3):227-238.

30. Association AP. Diagnostic and Statistical Manual of Mental Disorders. Washington, DC: American Psychiatric Association; 2000.

31. Kimberlin CL, Winterstein AG. Validity and reliability of measurement instruments used in research. American Journal of Health Systems Pharmacy. Dec 1 2008;65(23):2276-2284.

32. Richardson LP, McCauley E, Grossman DC, et al. Evaluation of the Patient Health Questionnaire-9 Item for detecting major depression among adolescents. Pediatrics. Dec 2010;126(6):1117-1123.

33. Wells VE, Klerman GL, Deykin EY. The prevalence of depressive symptoms in college students. Social Psychiatry. 1987;22(1):20-28.

34. Moreno MA, Jelenchick LA, Egan KG, et al. Feeling bad on Facebook: Depression disclosures by college students on a social networking site. Depression and Anxiety. Mar 112011.

35. Christofides E, Muise A, Desmarais S. Information disclosure and control on Facebook: Are they two sides of the same coin or two different processes? Cyberpsychology, Behavior and Social Networking. Mar 12009.

36. O'Grady MA, Wilson K, Harman JJ. Preliminary findings from a brief, peer-led safer sex intervention for college students living in residence halls. The Journal of Primary Prevention. 2009;30(6):716-731.

37. Raviv A, Raviv A, Vago-Gefen I, et al. The personal service gap: Factors affecting adolescents' willingness to seek help. Journal of Adolescence. 2009;32(3):483-499.

38. Haas A, Koestner B, Rosenberg J, et al. An interactive web-based method of outreach to college students at risk for suicide. Journal of American College Health. 2008;57(1):15-22.

39. Bull SS, Breslin LT, Wright EE, et al. Case study: An ethics case study of HIV prevention research on Facebook: The Just/Us Study. Journal of Pediatric Psychology. Feb 3.

40. Moreno MA, Fost NC, Christakis DA. Research ethics in the MySpace era. Pediatrics. Jan 2008;121(1):157-161.

41. Christensen H, Griffiths KM, Jorm AF. Delivering interventions for depression by using the internet: Randomised controlled trial. British Medical Journal. Jan 31 2004;328(7434):265. 